\title{
РЕАЛИЗАЦИЯ МОДУЛЯ ФОРМИРОВАНИЯ ПАКЕТОВ АДАПТИВНЫХ ТЕХНОЛОГИЙ ДЛЯ ЭКСПЕРТНОЙ СИСТЕМЫ ОПТИМАЛЬНОГО ЗЕМЛЕПОЛЬЗОВАНИЯ
}

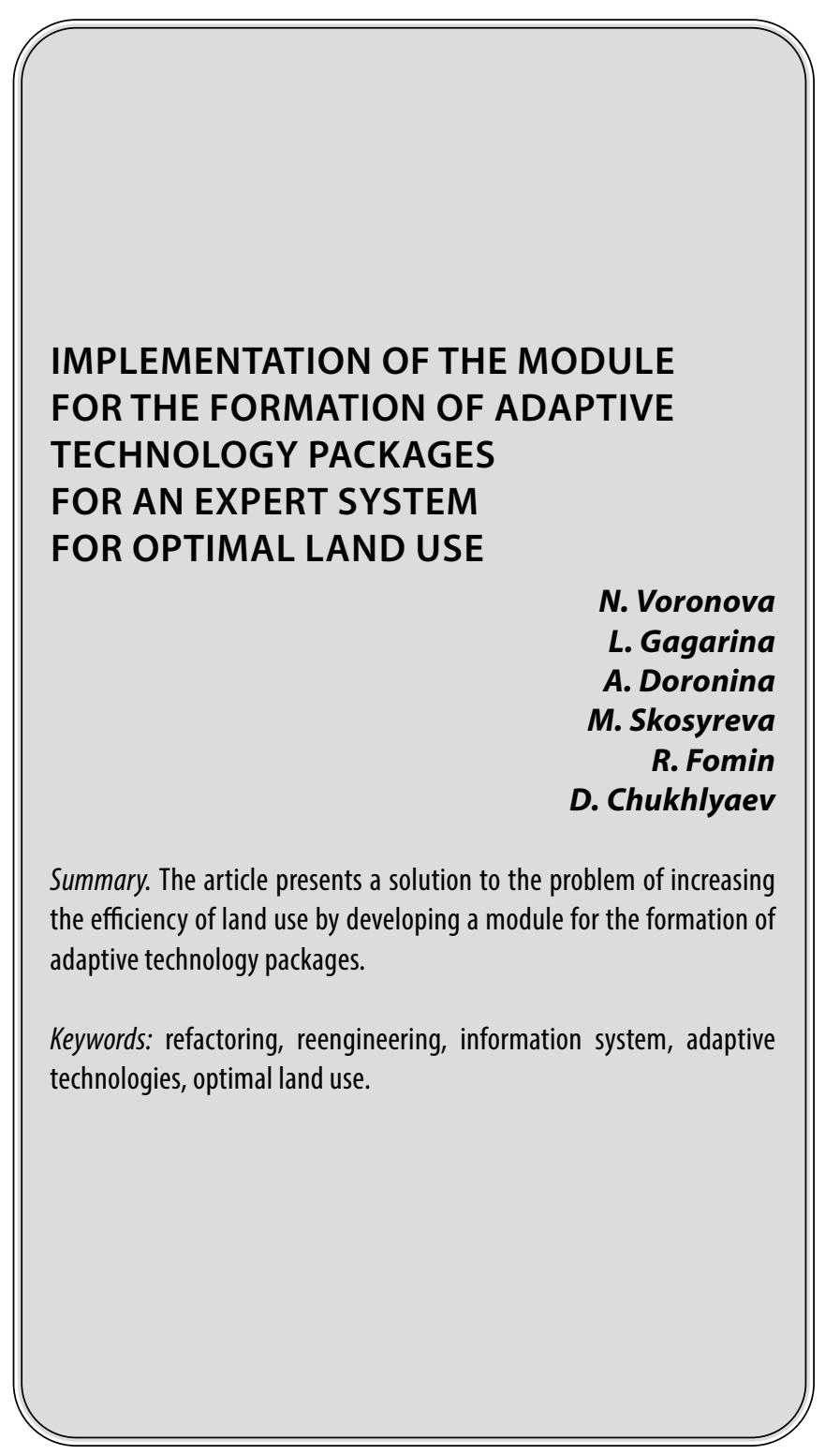

д ля динамического развития сельскохозяйственного производства необходимо создание информационной инфраструктуры. Особую роль при повышении уровня автоматизации и информатизации процессов играют информационные системы.

В настоящее время функционирует экспертная система оптимального землепользования (ЭСОЗ) [1], которая разрабатывается для ее дальнейшего исполь-
Воронова Наталья Михайловна

Н.с., Начиональный исследовательский университет «Московский институт электронной техники» «МИЭТ» nmvoronova@mail.ru

Гагарина Лариса Геннадьевна

Д.т.н., профессор, Национальный исследовательский университет «Московский институт электронной техники» «МИЭТ» gagar@bk.ru

Доронина Анна Александровна Национальный исследовательский университет «Московский институт электронной техники» «ИИЭТ doronina.anna.a@mail.ru

Скосырева Мария Сергеевна

Владимирский Государственный университет имени А.Г. и Н.Г. Столетовых, г. Владимир skosyreva.maria@mail.ru

Фомин Роман Андреевич

Национальный исследовательский университет «Московский институт электронной техники»

«ИИТ»

roman.a.fomin@mail.ru

Чухляев Дмитрий Алексеевич

Национальный исследовательский университет «Московский институт электронной техники»

«ИИЭТ

chukhlyaev.dmitry@mail.ru

Аннотация. В статье представлено решение проблемы повышения оперативности землепользования посредством разработки модуля формирования пакетов адаптивных технологий.

Ключевые слова: рефакторинг, реинженеринг, информационная система, адаптивные технологии, оптимальное землепользование.

зования агрономами, почвоведами, научными работниками и функционирует в двух режимах - в режиме без привязки интеллектуальной консультации к какому - либо земельному хозяйству и в режиме с привязкой. Актуальность системы определяется ее функционалом, который, тем не менее, является неполным. В целях модернизации ЭСОЗ необходимо проанализировать достоинства и недостатки действующих систем. 
Таблица 1. Особенности текущей реализации системы

\begin{tabular}{|c|c|c|}
\hline № $\pi / \Pi$ & $\begin{array}{l}\text { Особенности текущей } \\
\text { реализации }\end{array}$ & Недостатки \\
\hline 1 & $\begin{array}{l}\text { ArcView GIS - как средство } \\
\text { реализации }\end{array}$ & $\begin{array}{l}\text { не является бесплатным, что усложняет внедрение системы: у конечного } \\
\text { пользователя должна быть лицензия на использование ArcView GIS; } \\
\text { не является кроссплатформенным ПО, т.е. зависит от OC. }\end{array}$ \\
\hline 2 & $\begin{array}{l}\text { Использование версии ArcView } \\
\text { GIS3.1 }\end{array}$ & $\begin{array}{l}\text { морально устаревшая версия, возможности и функционал значительно уступают } \\
\text { последней версии 10.0. }\end{array}$ \\
\hline 4 & $\begin{array}{l}\text { Оконное приложение с цепочкой } \\
\text { диалоговых форм }\end{array}$ & $\begin{array}{l}\text { очень неудобная эргономика; } \\
\text { не презентабельный интерфейс; }\end{array}$ \\
\hline 5 & Отсутствие тестирования системы & $\begin{array}{l}\text { частично неработоспособный код; } \\
\text { отсутствие документированного кода. }\end{array}$ \\
\hline
\end{tabular}

Существует система интерактивного формирования пакетов адаптивных технологий «Агрокон», которая функционирует в трех режимах:

1. «Обработка поля фермерского хозяйства» (ОПФХ);

2. «Обработка поля севооборота коллективного хозяйства» (ОПКХ);

3. «Обработка севооборота коллективного хозяйства» (ОПКлХ) [2].

Текущая реализация системы имеет целый ряд недостатков (табл. 1). Процесс использования системы очень усложнен - зачастую требуется установка и администрирование вспомогательного программного обеспечения. На уровне представления данных режимы между собой никак не связаны - отсутствует единая база данных. В связи с чем необходимо осуществить кардинальный реинжиниринг и реализовать бизнес-логику более современными средствами разработки.

С целью устранения недостатков и наращивания функционала необходимо доработать систему ЭСО3, а именно разработать модуль формирования пакетов адаптивных технологий (ФПАТ).

\section{База знаний}

\section{$\ni \subset \bigcirc 3$}

База знаний ЭСОЗ состоит из двух модулей:

- модуль работы с базами данных;

- модуль формирования знаний.

Для представления знаний в системе ЭСОЗ используется продукционная модель, в рамках которой знания представляются в виде предложений типа:

«Если (условие), то (действие)».
В данном случае в качестве условия выступает предложение-образец, на основе которого в базе знаний выполняется поиск; действие - это операция, выполняемая в случае успешного поиска. Продукционная модель формирует базу знаний, состоящую из правил. Перебором этих правил управляет специальная программа, называемая машиной вывода. Наиболее распространенными формами вывода являются прямо и обратный вывод. При использовании прямого вывода перебор правил происходит от данных к цели; при использовании обратного - от цели к данным для ее подтверждения. Под данными понимаются некоторые исходные факты, на которых запускается машина вывода [3].

Исходя из режимов функционирования ЭСО3, все данные, содержащиеся в системе, представляют агрономические данные справочного характера, экспертные рекомендации по оптимальному адаптивно ландшафтному земледелию без привязки к земельному участку, а также данные конкретного земельного хозяйства.

В базе данных представлены:

- агроэкологические характеристики типов земли;

- параметры трех уровней интенсификации;

- характеристики всех возделываемых в зоне культур;

- 25 севооборотных схем, которые содержат различную специализацию от зерновых до кормовой направленности.

Также содержатся параметры:

- 8 видов основной обработки почвы;

- 25 комбинаций предпосевной обработки почвы и посева;

- 12 комбинаций по уходу за посевами; 


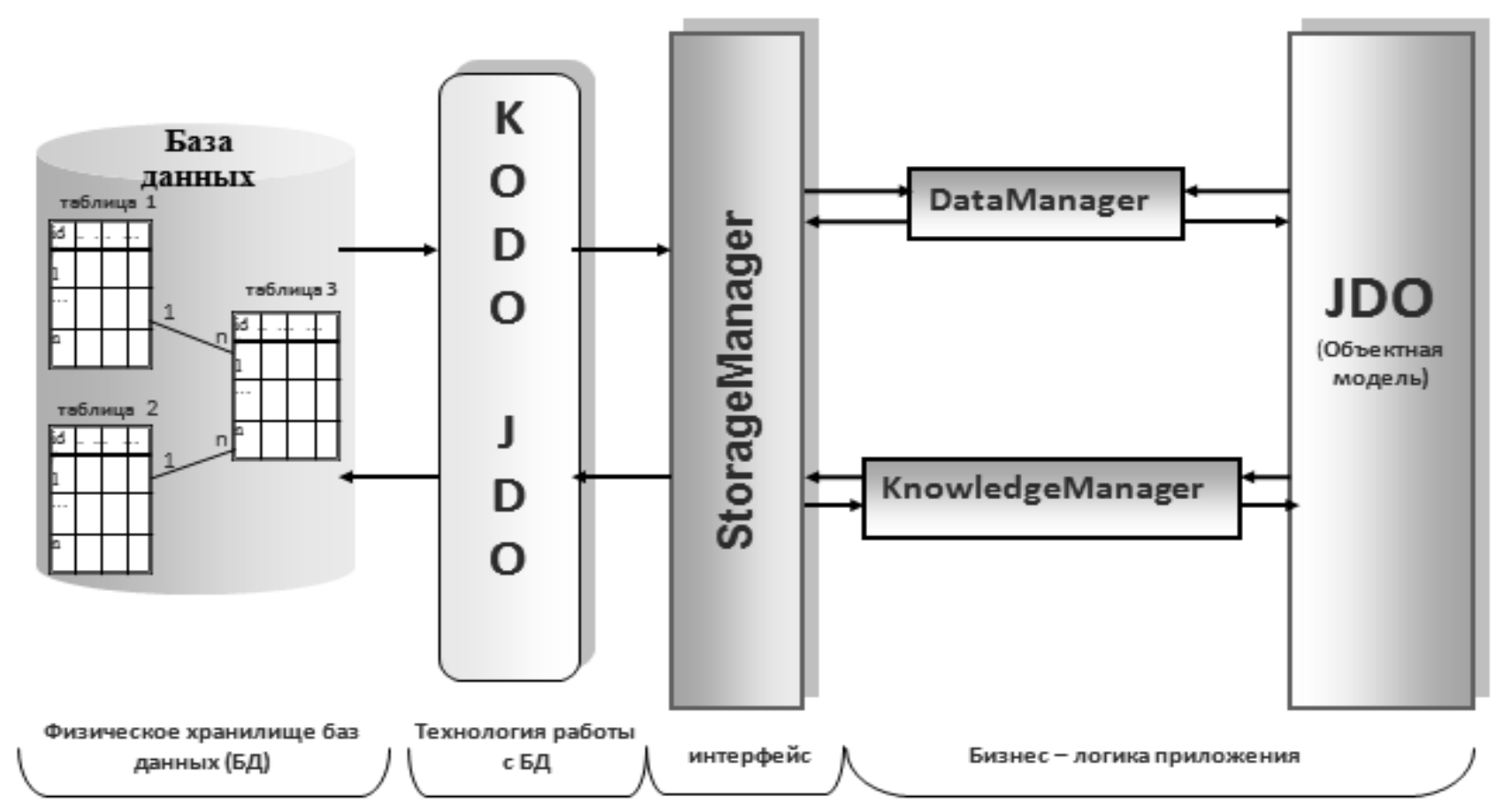

Рис. 1. Схема работы бизнес-логики приложения

- 10 комбинаций по уборке урожая;

- 13 схем применения удобрения.

Вся информация хранится в 52 таблицах, каждая из которых имеет так называемый паспорт с общим описание (назначением) таблиц и техническими характеристиками.

Данные в приложении описываются в виде объектной модели. Каждая таблица из базы данных соответствует отдельному классу в объектной модели. Связь классов объектной модели с таблицами базы данных организовывается через специальные файлы *.jdo и *. mapping в формате *.xml.

На уровне приложения обращение к данным происходит через специальный интерфейс StorageManager, в котором описаны все основные действия с данными без учета особенностей конкретной объектной модели.

Замодули работысданными изнаниями отвечаютдва утилитных класса: DataManager и KnowledgeManager. DataManager реализует запросы на получение справочной информации. KnowledgeManager формирует запросы на получение знаний.

На низком уровне с данными работает технология Kodo JDO, выполняя такие действия как: открытие со- единения с БД, формирование запросов на языке SQL и т.д. (рис. 1).

Экспертная система оптимального землепользования (ЭСО3) является web-приложением на платформе J2EE [4][5]. Схема данных размещена на сервере MySQL.

Приложение содержит все основные классы, описывающие основные бизнес-объекты и состоит из нескольких модулей:

- модуль работы с данными, который реализует запросы к базе данных;

- модуль формирования знаний;

web-модуль.

\section{Разработка моАуля ФПАТ}

Структура модуля ФПАТ реализовывает функционал системы «Агрокон». Согласно режиму проектирования системы «Агрокон», весь функционал можно разделить на 3 режима работы:

1. обработка произвольного поля;

2. обработка одного поля севооборота хозяйства;

3. обработка севооборотов хозяйства.

Каждый из режимов представляет определенный самостоятельный алгоритм формирования пакетов адаптивных технологий, поэтому в разделе указанные режимы должны быть независимы друг от друга. Также 


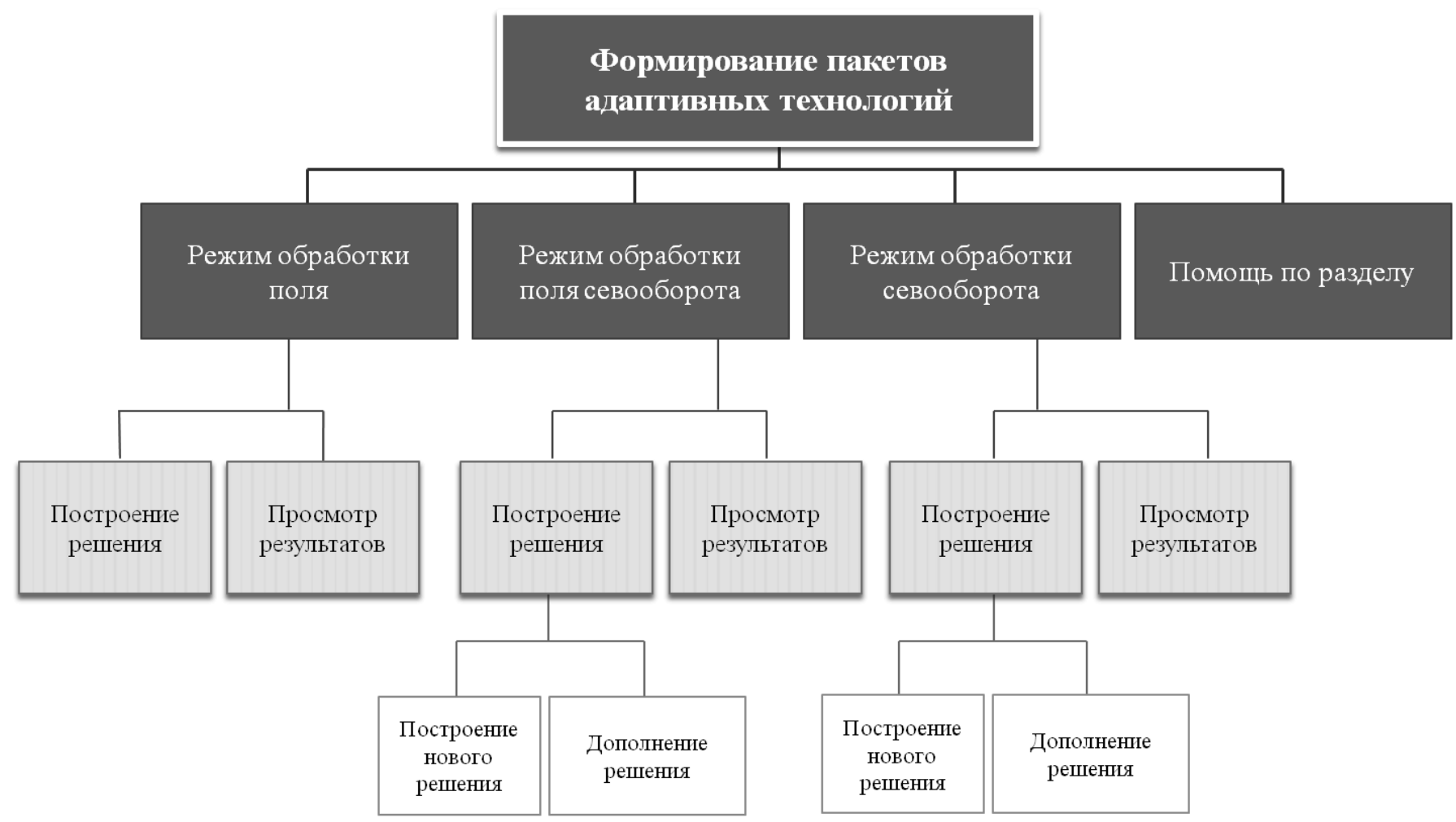

Рис. 2. Структура ФПАТ

необходимо обеспечить просмотр сохраненных пакетов технологий в рамках режима. С учетом этих требований каждый режим можно разделить на два подраздела:

1. построение решения;

2. просмотр результатов.

Кроме того, в режимах 2 и 3 при построении решения необходимо обеспечить как создание нового решения, так и дополнение существующего (рис. 2).

Модуль ФПАТ является частью экспертной системы, что подразумевает соответствие оформления страниц этого раздела общему стилистическому решению системы.

Анализ структуры web-интерфейса показал, что все страницы в зависимости от наполнения их центральной части можно поделить на три основных класса:

1. информационные - страница содержит только информационное наполнение без карты и элементов управления;

2. картографические с элементами управления картой - страница содержит карту и элементы управления картой;

3. информационно-картографические - страница содержит информационное наполнение, карту и элементы управления картой.
Страницы текущего раздела относятся к информационно-картографическим.

Режим обработки поля севооборота входит в состав раздела «Формирование пакетов адаптивных технологий». Согласно разработанной структуре, функционал данного режима реализован на трех страницах: «Построение нового решения», «Дополнение решения» (общий макет - «Построение решения») и «Результаты» (макет «Результаты»). Далее необходимо детализировать схему размещения элементов на панелях настройки параметров и таблиц просмотра результатов. Интерфейс страниц «Построение нового решения» и «Дополнение решения» аналогичен, за исключением первого элемента на панели настроек: на странице создания располагается поле ввода текста, а на странице дополнения - выпадающий список с вариантами созданных ранее решений.

Созданы html-страницы, где была прописана разметка, определяющая положение всех перечисленных элементов и добавлены элементы общего дизайн-макета и применены общие стили из CSS-файлов.

Модуль состоит из клиентской и серверной частей, тем самым реализуя технологию «клиент-сервер» (рис. 3). 

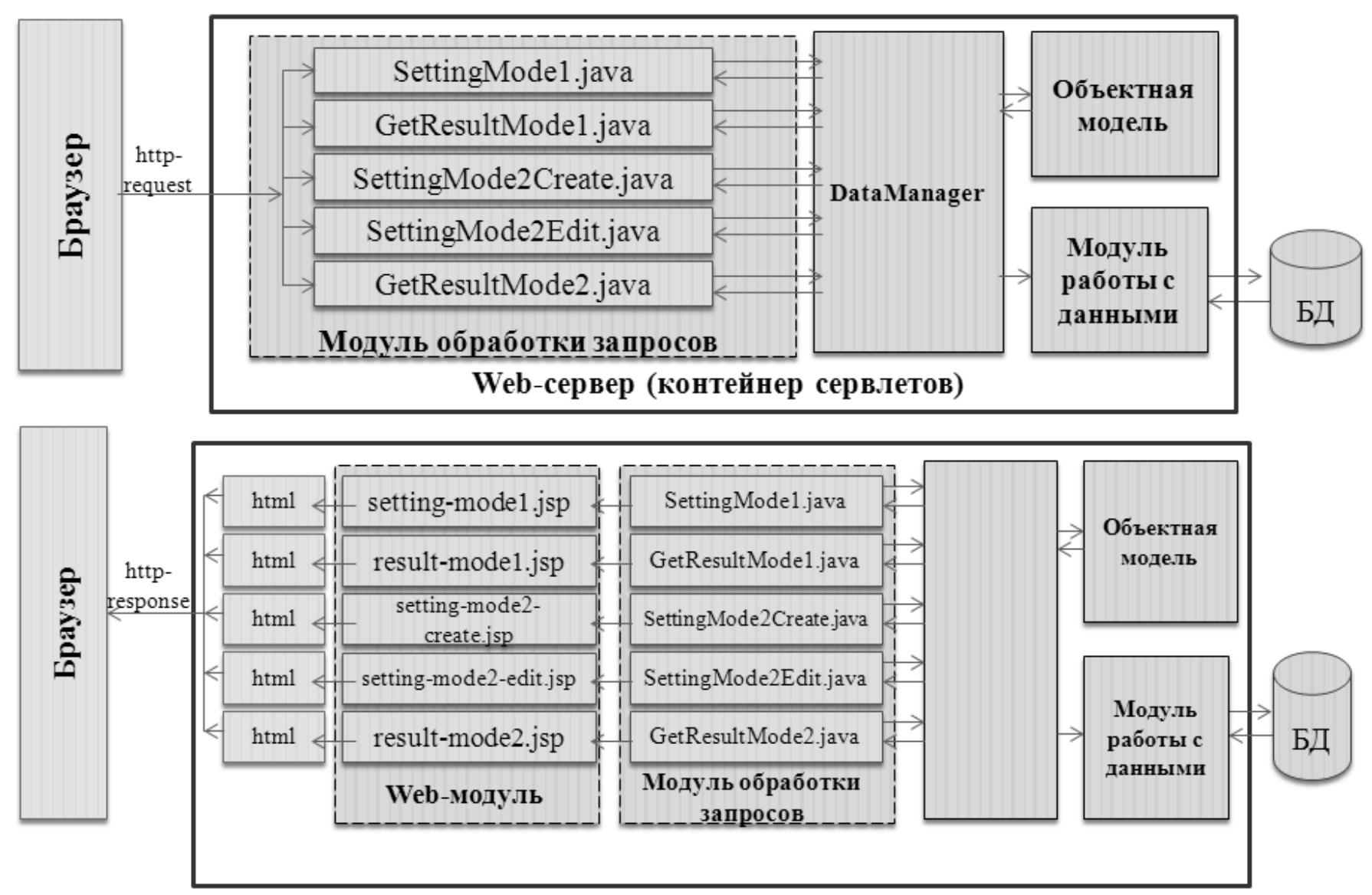

Рис. 3. Клиент-серверное взаимодействие

Клиентская часть реализует пользовательский интерфейс, формирует запросы к серверу и обрабатывает ответы от него. Эта часть в проекте представлена јsp-страницами. JSP-страница - это текстовый документ, содержащий статические исходные данные (в формате HTML или XML) и динамическое содержимое, которое конструируется JSP-элементами.

На основе разработанных HTML-страниц в модуле реализованы 6 страниц:

1. страница построения решения в режиме обработки одного поля;

2. страница просмотра результатов в режиме обработки одного поля;

3. страница построения нового решения в режиме обработки поля севооборота;

4. страница дополнения решения в режиме обработки поля севооборота;

5. страница просмотра результатов в режиме обработки поля севооборота.

Для формирования динамического содержимого перечисленных страниц использовалась библиотека пользовательских тегов JSTL.
Динамическое содержимое каждой страницы формируется при взаимодействии с сервером. Серверная часть получает запрос от клиента, выполняет вычисления, после этого формирует web-страницу и отправляет её клиенту по сети с использованием протокола НТТР. Обработка запросов пользователя происходит в специальном классе - сервлете.

\section{Режим ОПФХ}

При запуске модуля в режиме «Обработка поля фермерского хозяйства», начинается прохождение последовательной цепочки диалоговых окон: «Обработка поля фермерского хозяйства» - «Экспериментальная базовая урожайность» - «Площадь участка» - «Типы земли» — «Предшественник известен».

Логика формирования выводимого списка для разных режимов отличается - при выборе режима ОПФХ список предшественников формируется на основании выбранного ранее севооборота. Однако при проектировании обработки поля фермерского хозяйства севооборот выбирается уже после выбора предшественника, а поле не выбирается совсем (привязка к номеру 


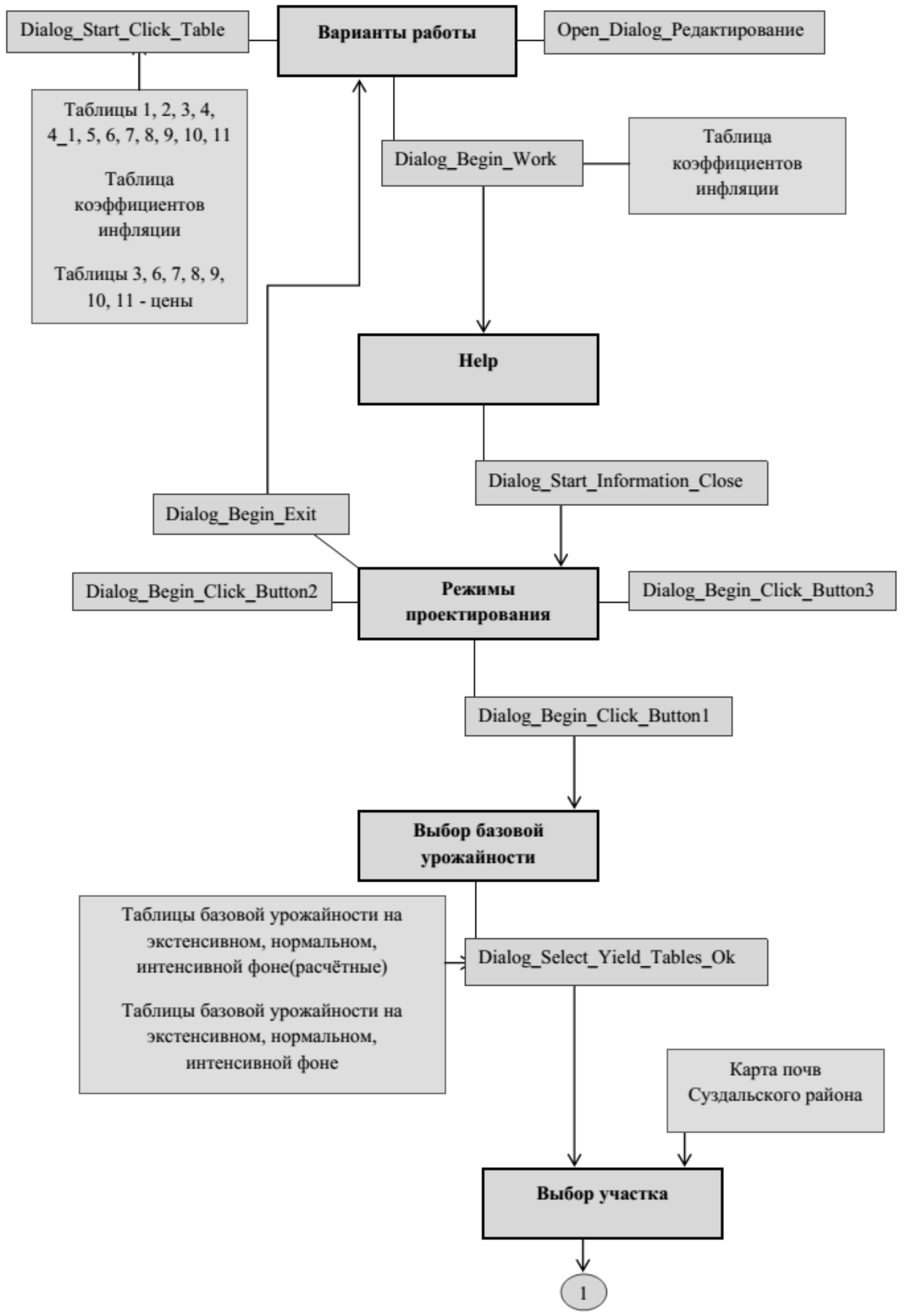

Рис. 4. Диаграмма последовательности для режима ОСКХ (продолжение на стр. 40) 


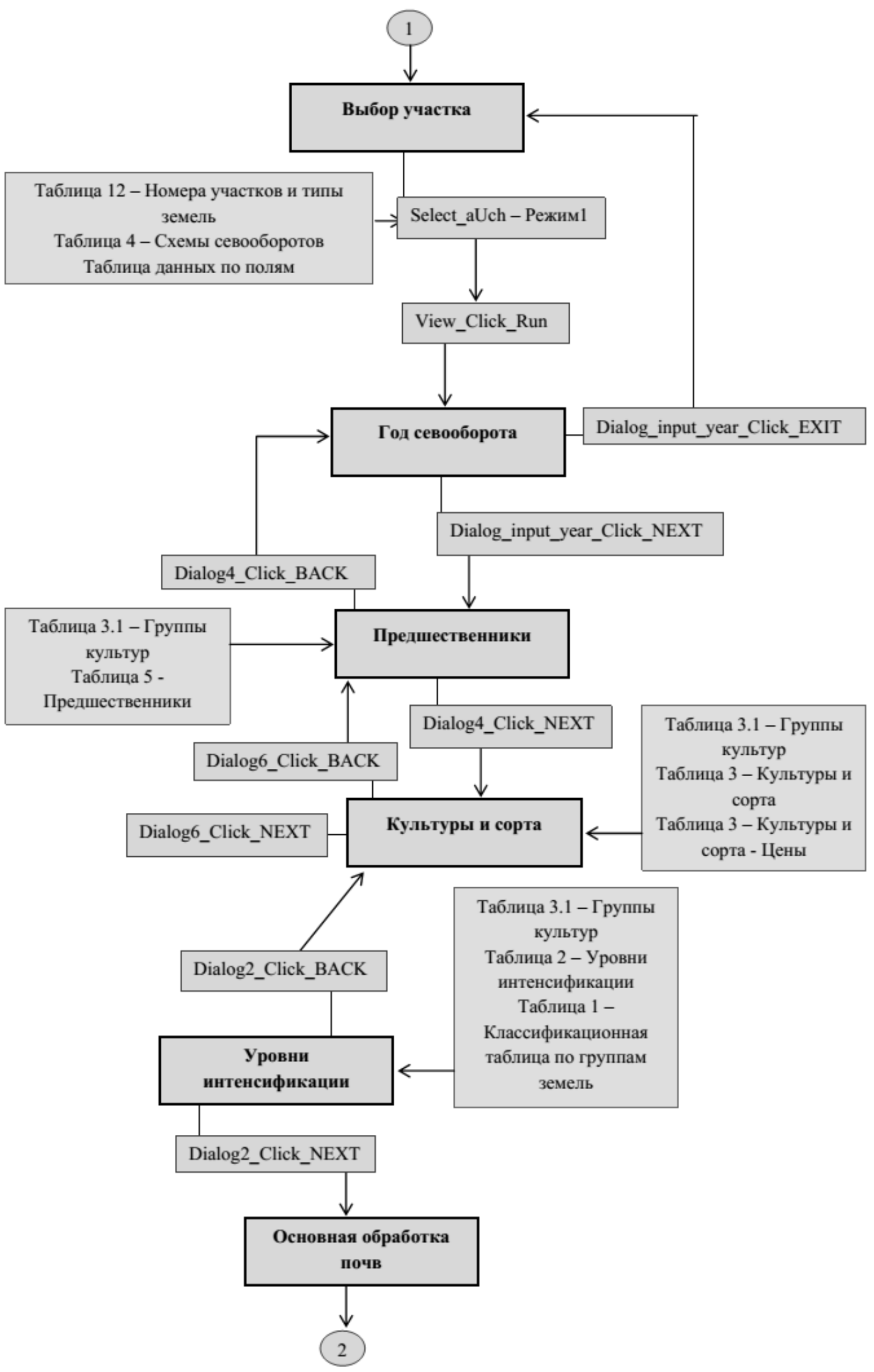

Рис. 4. Диаграмма последовательности для режима ОСКХ (продолжение на стр. 41) 


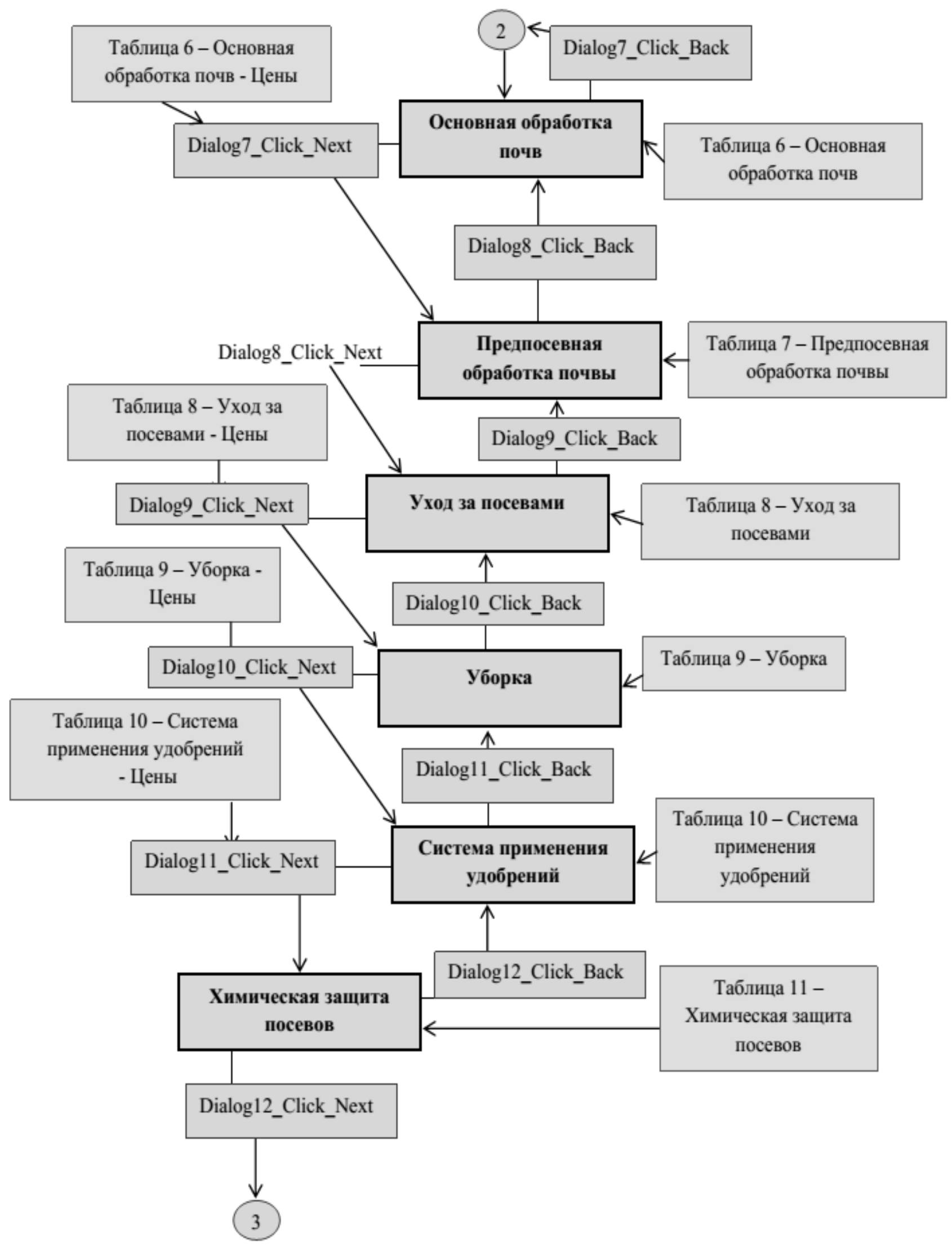

Рис. 4. Диаграмма последовательности для режима ОСКХ (продолжение на стр. 42) 


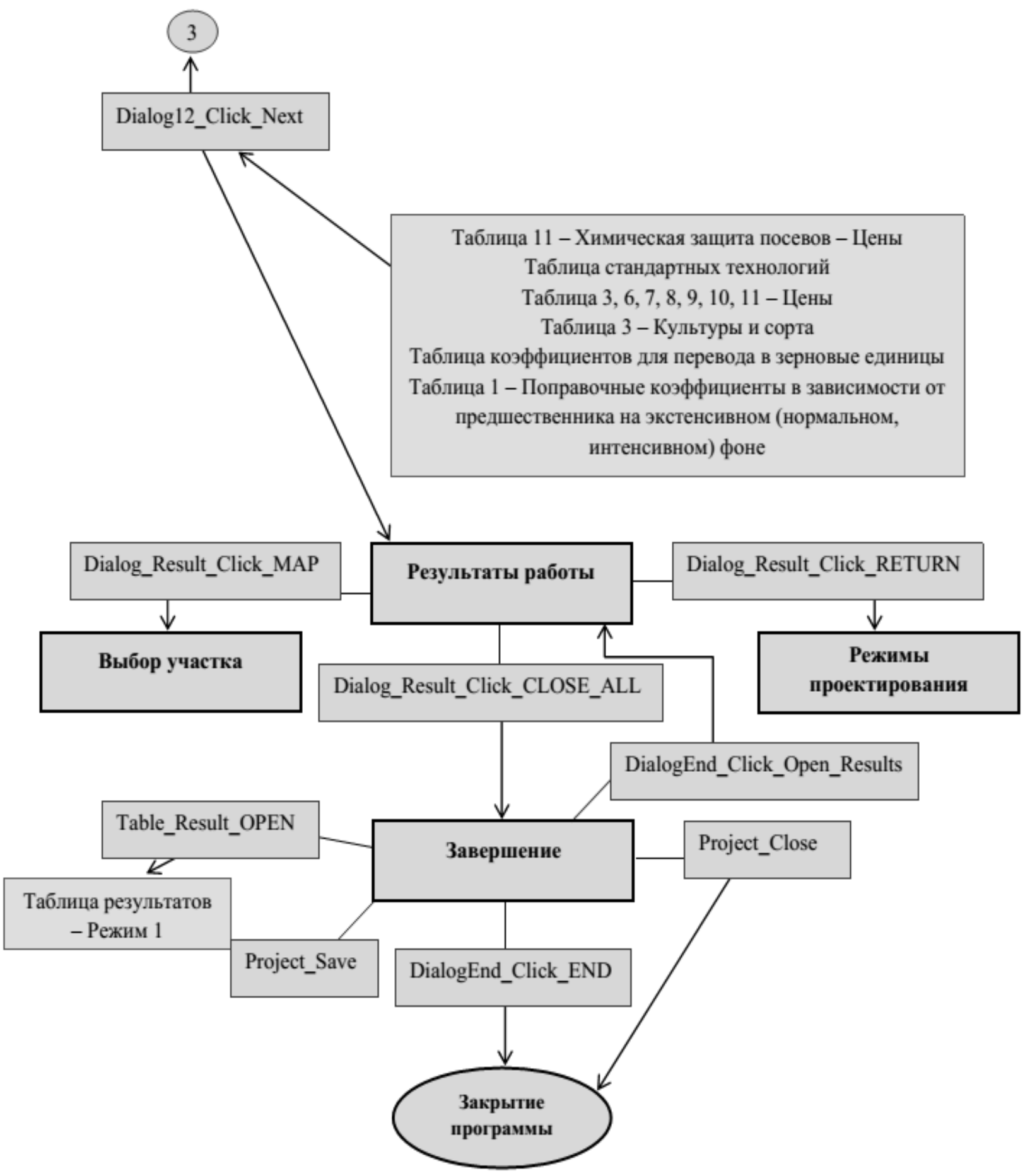

Рис. 4. Диаграмма последовательности для режима ОСКХ

поля осуществляется в другом режиме проектирования).

\section{Режим OCKX}

Запуск режима «Обработка поля севооборота коллективного хозяйства» начинается с прохождения по- следовательной цепочки диалоговых окон: «Обработка поля севооборота коллективного хозяйства» - «Экспериментальная базовая урожайность» - «Участок 4 5» - «Год севооборота: 2008» - «Предшественник». Диаграмма последовательности для режима обработки поля севооборота представлена на рисунке 4. При анализе алгоритма работы режима обработки поля севоо- 


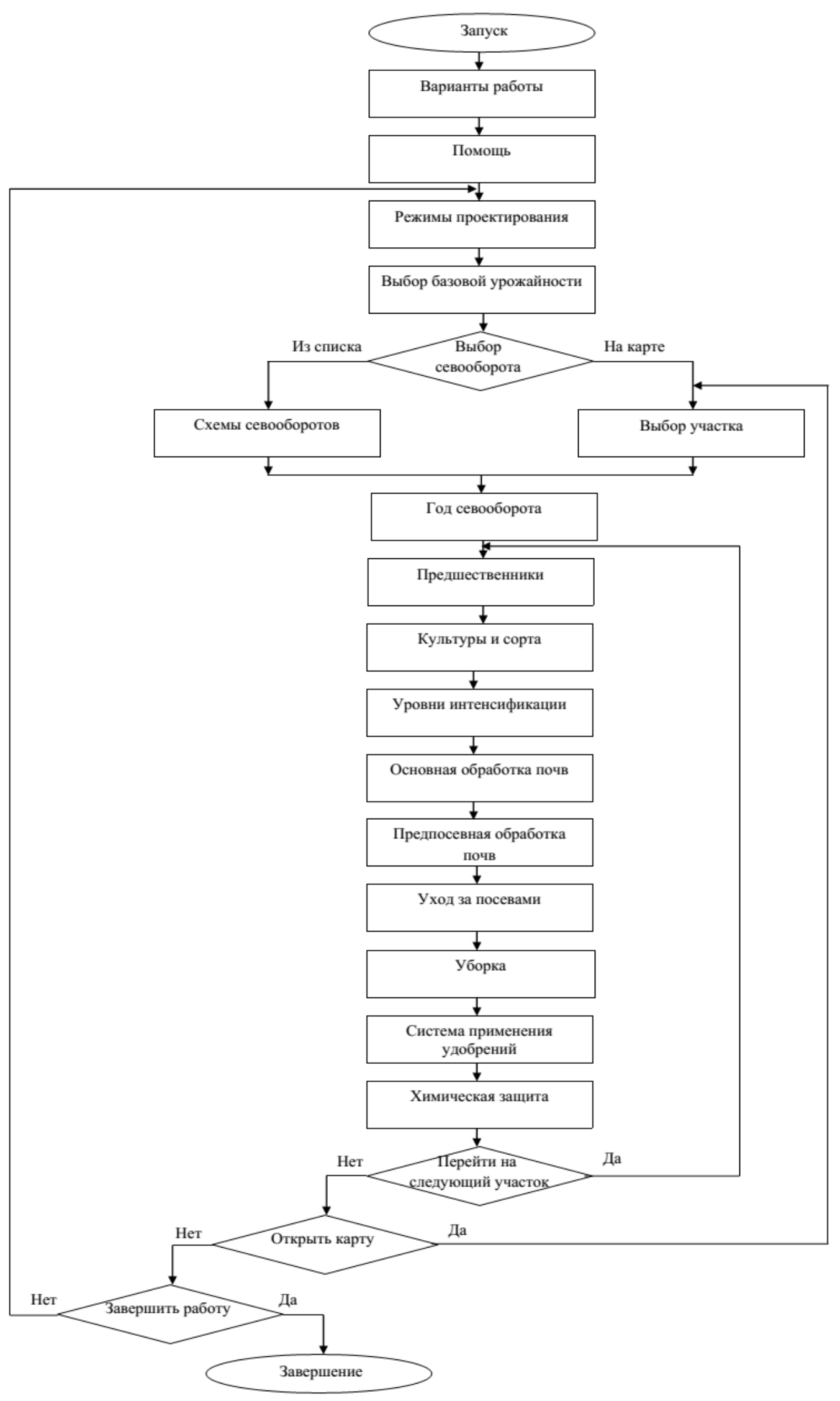

Рис. 5. Схема работы режима ОСКлХ 
борота и сравнении его с алгоритмом первого режима, отмечено, что на определенных этапах логика текущего режима совпадает с логикой режима ОПФХ.

\section{Режим OCK^X}

В процессе запуска модуля в режиме «Обработка севооборота коллективного хозяйства» (ОСКлХ) происходит прохождение последовательной цепочки диалоговых окон: «Обработка севооборота коллективного хозяйства» - «Экспериментальная базовая урожайность» - «Выбрать севооборот на карте» - выбираем севооборот - нажимаем кнопку «Предыдущий» в окне «Год севооборота» (рис. 5.).

\section{Зак^ючение}

В ходе работы выполнены все поставленные задачи, а именно:

1. проведена подготовка к реинжинирингу:

1. изучена система «Агрокон» и три режима проектирования в этой системе;

2. осуществлен поиск и устранение ошибок в системе «Агрокон», и корректность внесенных изменений подтверждена тестовыми запусками;

3. разработана спецификация системы «Агрокон».
4. реализован модуль «Формирование пакетов адаптивных технологий», в процессе реализации которого осуществлены:

1. модернизация класса, отвечающего за бизнес-логику режима обработки одного поля мелкого хозяйства;

2. перенос бизнес-логики режима обработки поля севооборота из системы «Агрокон» в модуль формирования пакетов адаптивных технологий;

3. разработка общей структуры раздела «Формирование пакетов адаптивных технологий» как части экспертной системы оптимального землепользования;

4. разработка дизайн-макетов страниц раздела;

5. редизайн рабочего интерфейса режима обработки одного поля в соответствии с разработанными макетами и общим интерфейсом системы;

6. рефакторинг функциональной части интерфейса режима обработки одного поля;

7. функциональная часть интерфейса режима обработки поля севооборота.

В перспективе предполагается проверка юзобильности тестирования на фокус-граппах пользователей и интеграция реализованного модуля на платформу экспертной системы.

\section{ЛИТЕРАТУРА}

1. Система агрономического консультирования «Агрокон» [Электронный ресурс]: Руководство пользователя / сост. Л.М. Воронова, Н.М. Воронова; Владим.гос.ун-т. — Владимир: изд-во Владим. гос. ун-та, 2013. - 13 с.

2. Экспертная система оптимального землепользования. URL: http://agroexpert.online

3. Джарратано Д., Райли Г. Экспертные системы. Принципы разработки и программирование.— М.: «000 И.Д. Вильямс», 2007.— 1152 с.

4. Фаулер М. Рефакторинг. Улучшение существующего кода. - СПб.: Символ-Плюс, 2008. - 432 с.

5. Реинжиниринг информационных систем [Электронный ресурс] — Режим доступа: http://5fan.ru/wievjob.php?id=19283, свободный. — Загл. с экрана.

( Воронова Наталья Михайловна ( nmvoronova@mail.ru ), Гагарина Лариса Геннадьевна ( gagar@bk.ru ),

Доронина Анна Александровна ( doronina.anna.а@mail.ru ), Скосырева Мария Сергеевна ( skosyreva.maria@mail.ru ),

Фомин Роман Андреевич ( roman.a.fomin@mail.ru ), Чухляев Дмитрий Алексеевич ( chukhlyaev.dmitry@mail.ru ).

Журнал «Современная наука: актуальные проблемы теории и практики» 